
\title{
RReserch Soute \\ The Relative Contribution of Large-Scale Circulation and Land Surface to Summer Precipitation Over Asian Mid-Low Latitudes
}

\section{Yue Chen}

Lanzhou University

Aihui Wang ( $\nabla$ wangaihui@mail.iap.ac.cn )

Institute of Atmospheric Physics Chinese Academy of Sciences https://orcid.org/0000-0002-4609-8774

\section{Guolin Feng}

China Meteorological Administration

\section{Research Article}

Keywords: Asian Precipitation, Dynamic Adjustment, Large-scale Circulation, Land-Atmosphere Coupling,

Posted Date: November 30th, 2021

DOl: https://doi.org/10.21203/rs.3.rs-1091305/v1

License: (c) (i) This work is licensed under a Creative Commons Attribution 4.0 International License. Read Full License 


\section{Abstract}

Understanding the contributions of large-scale atmospheric circulation and local land surface processes to precipitation is essentially important for the climate prediction. This study adopts a dynamic adjustment (DA) approach based on constructed circulation analogs to quantitatively isolate the contribution of atmospheric circulation to summer land precipitation ( $\mathrm{Pr}$ ) over Asian mid-low latitudes during 1980-2019. The atmospheric circulation factor is represented by the $500 \mathrm{hPa}$ geopotential height (Z500) from the fifth generation ECMWF reanalysis (ERA5), and the land surface factors, including soil moisture (SM) and net radiation and heat fluxes are from the products of the Global Land Data Assimilation System (GLDAS). The residual component after DA is regarded as the contribution from land surface processes via evaporation mainly resulting from SM. The results indicate that the key SM-Pr feedback areas are mainly located in northeast China and the northern Indian Peninsula. The key influencing area of Z500 on the land Pr anomaly shows a "---" tripole pattern in the mid-latitude region. Atmospheric circulation determines the magnitude of summer land Pr, while the residual components reflect the land-atmosphere coupling effect and dominate Pr trend. This conclusion is helpful for better understanding the evolution mechanism of summer climate over Asia mid-low latitudes and may also have application value for climate prediction.

\section{Introduction}

The Asian mid-low latitudes contain tropical and subtropical monsoon regions and "hot spots" for landatmosphere coupling, where accurately predicting precipitation $(\mathrm{Pr})$ is always a great challenge (Guo et al. 2006; Koster et al. 2006). As one of the typical monsoon climate areas in the world, the Pr in summer (JuneJuly-August, JJA) over East Asia, accounts for $52 \%$ of its annual total (Zhang 2015). Many studies have shown that large-scale atmospheric advection plays a leading role in the JJA Pr over Asian monsoon region, and the $500 \mathrm{hPa}$ circulation system has a close relationship with the East Asian summer monsoon (EASM) and Indian summer monsoon Pr variability (Aizen et al. 2001; Ding and Chan 2005; Huang et al. 2012; Meehl and Arblaster 2001). Therefore, the geopotential height (Z500) and other relevant indices at the $500 \mathrm{hPa}$ pressure level are often used as predictors of the JJA Pr over this region in operational climate prediction systems. The land surface processes also influence the formation and development of the land climate through the energy and water cycles between the land and atmosphere (Shukla and Mintz 1982). The results from numerical experiments indicate that soil moisture (SM) significantly influences Pr in boreal transition zones between wet and arid climates (Koster et al. 2004; Koster et al. 2006). Understanding the respective influences of the slowly varying land surface state and atmospheric components on Pr is very helpful for its prediction.

As an important land surface hydrological component, SM determines the partition of net radiation $\left(R_{\text {net }}\right)$ into sensible heat flux (SHF) and latent heat flux (LHF) (Koster et al. 2004). The SM anomalies state and its persistence are of great significance to the prediction of summer climate in the Northern Hemisphere (Seneviratne et al. 2010; Taylor et al. 2011), for instance, SM affects Pr predictability from subseasonal to seasonal scales (Koster et al. 2011; Seo et al. 2019). Studies have indicated that the mid-latitude climate changes in winter are dominated by the sea surface temperature (SST), while they are strongly influenced by 
affect Pr through water vapor recirculation (Eltahir and Bras 1996) or indirectly affect it through altering boundary layer dynamics and mesoscale circulation (Ek and Holtslag 2004; Taylor et al. 2011). These studies either analyze the influencing mechanism of SM on Pr or compare the impacts of SM and SST on Pr through initial condition sensitivity modeling experiments. However, few of these studies have addressed the relative contributions of atmospheric circulation and land surface components to land Pr over Asian midlow latitudes. It has been revealed that SM anomalies may last for several weeks to months. Therefore, it could influence the successive Pr through SM-Pr feedback mechanism (Jones and Brunsell 2009). Besides, there are many other sources of predictability for Asian summer Pr, such as Arctic sea ice, SST and Eurasian snow cover. Among them, the impacts of sea surface temperature, sea ice, and remote snow cover on inland Pr are mainly achieved by adjusting the atmospheric circulation (Barnett et al. 1989; Goddard et al. 2001; Trenberth et al. 1998; Wu et al. 2016), while the local snow melt in spring may also influence the SM through its memory to impact subsequent soil heat and water properties in summer (Yang and Wang 2019). Therefore, it is reasonable and ideal to use Z500 and SM as the respective indicators to measure the sources of land Pr in Asian mid-low latitudes.

The dynamic adjustment (DA) approach has been developed to isolate the climate change caused by atmospheric circulation (Deser et al. 2016). Previous DA research has highlighted the importance of the atmospheric dynamic effect, described by sea level pressure (SLP), to the observed trends in the Northern Hemisphere cold season surface air temperature (SAT) over Europe (Merrifield et al. 2017; Smoliak et al. 2015). Based on the fact that the SLP is less affected by human activities, much previous DA research has focused on investigating the mechanisms of SAT change caused by the natural climate variability (Wallace et al. 2012). Some studies have also adopted DA to isolate the effects of specific atmospheric teleconnection patterns and major geopotential height modes on terrestrial climate change (Nicolai-Shaw et al. 2016; Saffioti et al. 2016). For instance, Saffioti et al. (2016) applied DA to investigate the influence of atmospheric circulation on the winter climate in Europe based on a global climate model ensemble and indicated that the internal atmospheric variability had a significant impact on the winter Pr trend in part of Europe. The above studies have proven that DA is a useful and effective approach for separating the contributions of atmospheric circulation patterns to the climate. However, DA has not been used to explore the influence of large-scale circulation patterns on the land Pr in Asian Mid-Low Latitudes.

The main purpose of this study is to quantitatively separate the contributions of atmospheric circulation and local evapotranspiration (ET) to summer Pr over Asian mid-low latitudes. Z500 is used to represent the component of atmospheric circulation, and SM is used as a comprehensive indicator of land surface processes. To execute DA, the constructed circulation analog (CCA) approach is applied to identify the influence of atmospheric circulation on summer Pr. The residual Pr after DA is defined as the contribution of the land surface processes. Finally, the physical mechanism of land-atmosphere coupling on Pr is intensively explored.

The paper is organized as follows. The reanalysis datasets are described in Section 2. Section 3 describes the DA-CCA approach and other analysis methods used in this study. Section 4 analyzes the relationships between summer land Pr in Asian mid-low latitudes and Z500/SM and the characteristics of the circulation 


\section{Data}

\subsection{GLDAS products}

Global land data assimilation system (GLDAS) products have been widely used in both climate and hydrology research in Asia (Wang et al. 2016). The $1^{\circ} \times 1^{\circ}$ monthly GLDAS 2.0 product from the Noah Land Surface Model is available for 1980-2014 (Beaudoing and Rodell 2019), while the GLDAS 2.1 products are available since 2000 (Beaudoing and Rodell 2020). Compared to GLDAS-2.0, GLDAS-2.1 adopts additional state-of-art observation data in the construction of the atmospheric forcing dataset and better preserves the consistency of the long-term climatology

(https://hydro1.gesdisc.eosdis.nasa.gov/data/GLDAS/GLDAS_NOAH10_M.2.1/doc/README_GLDAS2.pdf). For example, the radiation flux fields in GLDAS-2.1 are bias-corrected byproducts from both the Air Force Weather Agency's AGRicultural METeorological modeling system (AGRMET) and the well-validated Surface Radiation Budget (SRB) (2002-2007). The evaluation has also shown that the GLDAS-2.1 Pr is closer to the gauge-based observations than that in GLDAS-2.0 on monthly scale in the Tibetan Plateau (Qi et al. 2018).

The GLDAS-Noah dataset provides SM in four soil depth layers: 0-10 cm, 10-40 cm, 40-100 cm, and 100-200 $\mathrm{cm}$. The JJA Pr over the Asian mid-low latitudes (Fig. 1a) land area accounts for $50.81 \%$ and $47.61 \%$ of the annual total Pr in GLDAS-2.0 and GLDAS-2.1, respectively. Figure 2 shows the areal-averaged time series and linear trends of seven variables across Asian mid-low latitudes during 1980-2019 in GLDAS-2.0 and GLDAS-2.1. Both Pr and SM from two versions of GLDAS products show substantially differences during the overlapping period, especially from 2002 to 2012. During the overlapping period from 2000 to 2014, the mean Pr in GLDAS-2.1 (3.58 mm/day) is larger than that in GLDAS-2.0 (3.38 mm/day), and the magnitude of increasing Pr trend is also higher in the latter version $(5.29 \mathrm{~mm} / \mathrm{a})$ than that in the former version $(1.27$ $\mathrm{mm} / \mathrm{a}$ ) (Table 1). Correspondingly, the SM in the latter version was also significantly higher than that in GLDAS-2.0 during 2007-2011, and soil in both products display strong wetting trend (Table1). Research has shown that Pr in GLDAS-2.1 is generally closer to observations than the GLDAS-2.0 on average, although both datasets underestimate Pr in majority river basins in China (Qi et al. 2020). The large differences in radiation and turbulent fluxes between the two versions may be due to the bias-corrected of AGRMET radiation fields and SRB in the GLDAS-2.1 dataset

(https://hydro1.gesdisc.eosdis.nasa.gov/data/GLDAS/GLDAS_NOAH10_M.2.1/doc/README_GLDAS2.pdf). Therefore, it can conclude that GLDAS-2.1 is overall more reliable than GLDAS-2.0 over land area in Asia.

To obtain continuous 40-year (1980-2019) Pr and land surface products, the differences in multiyear averages between GLDAS-2.1 and GLDAS-2.0 during the overlapping period (2000-2014) were computed and then added to the corresponding variable of GLDAS-2.0 for each year during 1980-1999. The biascorrected GLDAS-2.0 for the period of 1980-1999 and that of GLDAS 2.1 for the period of 2000-2019 were then merged to form a continuous long-term dataset. In this study, the monthly land total Pr, SM, LHF, SHF, ground heat flux (GHF), net shortwave radiation flux $\left(\mathrm{SW}_{\text {net }}\right)$ and net longwave radiation flux $\left(\mathrm{LW}_{\text {net }}\right)$ from the merged GLDAS dataset for the period of 1980-2019 over the Asian mid-low latitudes land area were used. In the following analysis, the net ground radiation was computed from $R_{\text {net }}=S W_{\text {net }}-L W_{\text {net }}$. Because 
transpiration affected by SM should also be discussed within this depth. Therefore, the SM in the $0-40 \mathrm{~cm}$ layer (i.e., the summation of the upper two soil layers) was used in this study.

\subsection{ERA5 products}

ERA5 is the fifth generation ECMWF reanalysis product for the global climate and weather and has been available since 1979 (Hersbach et al. 2020). The atmospheric model used to derive the ERA5 products has 137 hybrid sigma/pressure vertical levels with the top level at $0.01 \mathrm{hPa}$. The advanced 4D-Var data assimilation system was incorporated into the ECMWF's Integrated Forecast System (IFS). Compared to ERA-Interim, ERA5 benefits from many improvements, including more enriched observation datasets and advanced assimilation systems (Hersbach et al. 2020). Because the ERA5 product has a relatively high resolution $\left(0.25^{\circ} \times 0.25^{\circ}\right)$ and a state-of-the-art global atmospheric reanalysis, it has been applied for investigating synoptic-scale extratropical circulation, allowing for detailed study of atmospheric motion features (Rohrer et al. 2020). In this study, we used the monthly 500 hPa geopotential height (Z500), vertical integral of water vapor fluxes from the land surface to the top of the atmosphere and the planetary boundary layer height (PBLH) from the ERA5 products for the period of 1980-2019. The ECMWF convention for vertical fluxes is positively downward. All datasets were interpolated to $1^{\circ} \times 1^{\circ}$ to match the horizontal resolution of the merged GLDAS dataset. From the map distribution of climatology mean of JJA Pr and vertical integral of horizonal water vapor flux (Fig. 1b). It can be seen that regions with large water vapor convergences are well matched with the high Pr. This indicates that the water vapor transport through the large-scale atmospheric circulation is the dominant water sources of Pr in the Asian mid-low latitude land areas.

\section{Method}

\subsection{Dynamic adjustment using the constructed circulation analog approach}

The CAA approach, first proposed by Lorenz (1969), is a statistical method for weather and climate prediction. In recent decades, the CAA has been developed and widely applied to infer the dynamic contribution of atmospheric circulation to climate trends (Deser et al. 2016; Hurrell 1995). Because the origins of moisture for land Pr come from remote areas (e.g., ocean surfaces) through the advection of large-scale circulation and/or local ET, we employed the DA-CAA to isolate the contributions of the above two components to the JJA Pr in the study region.

In the following, we briefly describe the DA-CCA procedure used in the current study, and a detailed description of the method can be found in Deser et al. (2016). For each summer month during the period of $1980-2019$, the domain of $0^{\circ}-80^{\circ} \mathrm{N}, 20 \mathrm{E}^{\circ}-180^{\circ} \mathrm{E}$ was used to compose Z500 analogs (Fig. 1a). Taking June 1980 as an illustrated example, we randomly subsampled 30 from 39 June (after excluding the target month, i.e., June 1980) Z500 fields, and then they were used to composite the optimally linear fitting of the target month, which was then denoted as the first circulation analog of June 1980 (C1). Having applied the above optimallv linear fittina procedure to the corresponding 30 June Pr fields, we obtained the first optimal Loading [MathJax]/jax/output/CommonHTML/fonts/TeX/fontdata.js 
fitting Pr component field (P1) for the target month that was caused by atmospheric circulation. This random sampling procedure was then repeated 100 times to reduce the sampling errors in previous study (Merrifield et al. 2017). To test the impact of resampling times on the results, four groups of tests including $100,200,500$ and 1000 times of resampling are conducted and the results among those tests show very slightly different (the correlation coefficients between the calculated results are greater than 0.9 at the $5 \%$ significance level). In order to reduce the sample error to large extent, the DA-CCA results obtained after repeated 1000 times of resampling are used in our study. The average of $1000 \mathrm{Z} 500$ analogs (C1, C2..., C1000) and their associated Pr components (P1, P2..., P1000) were used to quantitatively estimate the effect of atmospheric circulation on $\mathrm{Pr}$ in the target month. After repeating the above steps for all 120 summer months, we obtained a complete reconstruction of the dynamically induced Pr component in each month, denoted as Pr-Circ. Finally, the Pr-Circ component was subtracted from the raw Pr field of each month, and the residuals (Pr-Res) were interpreted as being primarily driven by land surface processes (Merrifield et al. 2017).

\subsection{Other analysis methods}

To facilitate analyze the relationships between different variables, each variable was firstly normalized by subtracting its long-term monthly mean and then dividing by its temporal standard deviation (STD). The normalization results in an approximately normal distribution of sample data with a mean of 0 and a variance of 1. Considering the lagging feedback of SM to Pr, as well as reducing the simultaneous influence of Pr on SM in the statistical analysis of SM-Pr feedback, we chose the SM of one month ahead of Pr for the following analysis.

The singular value decomposition (SVD) method is commonly used to investigate the collocation patterns of two meteorological quantities (Prohaska 1976). Using the empirical orthogonal function (EOF) analysis technique, the SVD method aims to identify the high-relationship area of two fields by decomposing the cross-correlation coefficients between two meteorological fields. In SVD, the correlation coefficient between one variable field (left field) and the time coefficient of the other variable (right field) in the paired element fields is called the heterogeneous correlation coefficient, and its spatial distribution represents the relationship pattern of two variables. Where the heterogeneous correlation passes significance test is the key area of the interaction between the two variable fields. The principle and applicability of SVD are described in detail in matrix theory (Wallace et al. 1992).

SVD analysis usually requires a sample size greater than the number of spatial grids in both target variable fields, which is often difficult to achieve in climate research. Therefore, when only limited climate data are available, the Monte Carlo technique is used to test the significance of SVD modes and then to determine whether the result is signal or noise. In this study, the random number generator was used to first produce two data matrices with a Gaussian distribution 100 times, and then they were used to reperform SVD calculations. If the variance contribution of the original SVD modes was greater than the $95 \%$ quantile among the above 100 results, the pair of SVD modes was considered to be significant at the $95 \%$ significance level (Wallace et al. 1992). 
In this study, Pr was regarded as the right field, and Z500 and SM were successively used as the left field. The monthly Pr, Z500 and SM were firstly converted to the anomaly by subtracting the corresponding monthly climatology for 1980-2017, and then their JJA mean were used to carry out SVD analysis. Before performing SVD analysis, both latitudinal weighing and normalization were applied to all variable fields, and then 40 dimensionless JJA mean variable fields were obtained. The first pair of significant SVD modes and the corresponding distribution pattern of the heterogeneous correlation coefficient were the key regions of the interaction between the two fields, which will be analyzed in detail below.

\section{Results}

\subsection{Relationship between JJA Pr and Z500 and SM over Asian mid-low latitudes}

Figure 3 shows the climatology of the JJA land surface hydrological variables from the merged GLDAS dataset for 1980-2019 over Asian mid-low latitudes. In order to avoid the overlapping between periods of MJJ SM and JJA Pr, the correlation of previous SM and Pr was firstly calculated month by month. For example, the correlation analysis of SM in May and Pr in June was conducted, and then Fig. 3b is obtained by averaging the correlation coefficients of three months. There is a clear spatial gradient in the distributions of Pr (Fig. 3a) and SM (Fig. 3b), showing gradual changes from dry in the northwest inland area to wet in the southeast coastal area. The wettest region appears in the South Asia land area, while the driest regions are around $40^{\circ} \mathrm{N}$. Regional land-atmosphere coupling intensity is dependent on the water and energy at the land surface. The spatial gradient variables in Fig. 3 indicate that climate and land surface heat fluxes over Asian mid-low latitudes are substantially variable from inland to coastal regions. The upward $L_{\text {net }}$ and downward $\mathrm{SW}_{\text {net }}$ over Asian mid-low latitudes are both strongest in the western part and weakest in the southeastern coastal area (Figs. $3 c, d$ ). The $R_{\text {net }}$ computed as the difference between $S_{\text {net }}$ and $L W_{\text {net }}$ is then decomposed into the SHF, LHF and GHF. Both SHF and LHF show similarly spatial distribution as that of SM, but SHF displays an opposite gradient (Figs. 3e, f). Except for the southern region, GHF is positive, that is, downward, throughout the study area (Fig. $3 \mathrm{~g}$ ). The $\mathrm{R}_{\text {net }}$ is mainly consist of SHF in the western region, while it is dominant by LHF in the other regions, especially in the southeast, and the GHF is relatively small in the whole region.

Figure 4a presents the normalized annual time series of the MJJ SM, JJA Pr and Z500 averaged over Asian mid-low latitudes. Strong covariability appears in Pr and SM ( $r=0.63, a=0.05)$, and the STDs are $0.13,0.14$ and 0.45 for the Pr and 0-40 cm normalized SM and Z500, respectively. The correlation coefficient of Pr-SM in Fig. 4b can be regarded as the feedback strength of Pr to antecedent SM forcing. The wet (dry) shallow layer soil (0-40 cm) during May-June-July will induce more (less) Pr in the succedent month over most of the study areas (Fig. 4b). Pr in the southeast of the study area is affected by the EASM, where the correlation coefficient between Pr and Z500 is opposite to that in the western and northern inland regions (Fig. 4c).

The regions with significant Pr-SM correlation and Pr-Z500 correlation are not independent. Thus, it is necessarv to Derform further SVD analvsis to extract the main coupling signals between the Z500/SM and Loading [MathJax]/jax/output/CommonHTML/fonts/TeX/fontdata.js 
Pr fields. Using the MJJ SM and JJA Z500 as the left fields respectively and the JJA Pr as the right field, two sets of SVD analyses are conducted (Fig. 5). The squared covariance fraction (SCF) of the first SVD mode (SVD1) of the JJA Pr and Z500 (SM) is $30.75 \%$ (33.31\%). The Monte Carlo technique test shows that the first pair of SVD modes in both groups are significant at the $95 \%$ confidence level. There is an obvious "+-+" meridional wave train in Z500, and the negative centers on the west side of Lake Baikal and low latitude zone are the key regions affecting $\operatorname{Pr}$ (Fig. 5a). The heterogeneous correlation coefficients between $\operatorname{Pr}$ and Z500 (Fig. 5c) are significantly negative in the west of the study area (Fig. 5c). When the negative Z500 anomaly exhibits the abnormal distribution shown in Fig. 5a, the location of WPSH is to the north as compared with the normal situation, which is conducive to the transportation of water vapor to the north. While the Kazakh hills to the Tibetan Plateau are controlled by anticyclone, which is unfavorable for $\mathrm{Pr}$ formation. The results show that when Z500 decreases near the Mongolian Plateau and low latitudes, $\mathrm{Pr}$ decreases near the Tibetan Plateau and increases over the Sayan Mountains, the Greater Hinggan Mountains, north China and the eastern Iranian Plateau.

Similarly, the heterogeneous correlation coefficient between the SVD1s of Pr and SM is shown in Figs. 5b, d. The correlation coefficient of left field (SM) over both Mongolian Plateau and Tibetan Plateau are significant negative, while it is significantly positive over the rest of the study area (Fig. 5b). The corresponding heterogeneous correlation coefficient of SM is much similar to that of $\operatorname{Pr}$ (Fig. 5d), reflecting the local coupling of antecedent SM and Pr. According to the above analysis, the key areas where SM and Z500 affects Pr obtained by the SVD method partly overlapped. Above analysis is only the interaction from a statistical point of view but cannot reveal the physical mechanisms driving the effects of Z500 and SM on Pr.

\subsection{Effects of Z500 and SM on the JJA land Pr over Asian mid-low latitudes}

To separate the contributions of large-scale circulation and local ET to Pr, the DA approach is used to decompose the contributions into two parts, Pr-Circ and Pr-Res (Section 2.3). The physical meaning of PrCirc is noticeable and indicates that water vapor for Pr formation is transported by large-scale atmospheric circulation factors (e.g., westerly wind) from faraway oceans. To verify the speculation of the physical meaning of Pr-Res, we compute and analyze the correlation coefficients between the JJA Pr-Res anomaly and the thermodynamic/dynamic quantities at the land surface after removing their corresponding seasonal cycles (Fig. 6).

The total net surface radiation consists of GHF, SHF and LHF, representing the major heat fluxes of land surface processes. Considering that the magnitude of GHF is relatively small and nearly time invariant, only the relationships between the Pr-Res and SHF, LHF and PBLH are investigated. The correlation between PrRes and LHF shows strongly and significantly positive in the arid and semiarid regions, but it is significantly negative in southeast China, Korean Peninsula and Japan (Fig. 6a). Pr-Res and SHF are negatively correlated across almost all of the study region (Fig. 6b). The above results are consistent with previous work. For instance, Liu et al. (2017) found that dry soil in spring in eastern China would lead to an increase in SHF from late sprina to summer and then enhance Pr in northeastern China. Because ET and SHF Loading [MathJax]/jax/output/CommonHTML/fonts/TeX/fontdata.js 
anomalies may add perturbations in atmospheric humidity and temperature, they will affect the development and entrainment of the boundary layer (Ek and Holtslag 2004). Although the moisture for Pr might be transported from faraway ocean evaporation, local SM conditions influence the boundary layer stability and growth, which determines when and where it is raining. Figure $6 \mathrm{c}$ shows that the PBLH is negatively correlated with Pr-Res in most part of study region except for Kazakh hills and central China. When the soil is relatively wet, the surface net radiation is mainly distributed as LHF, that is, less SHF and more ET, so that SAT in the boundary layer decreases and the relative humidity increases, which then suppress the development of Pr. Because a high PBLH is favorable for the formation of Pr, the relationship between Pr-Res and PBLH indicates that land surface processes may indirectly impact boundary layer stability and growth. Thus, it can be concluded that Pr-Res can represent the portion of Pr induced by changes in land surface processes.

To quantify the independent effects of two factors on Pr, the SVD method is again used to analyze the relationships between Z500 and Pr-Circ and between SM and Pr-Res (Fig. 7). The results are then compared with SVD based on the original Pr and two factors (Section 3.1 and Fig. 5). The spatial distribution of the SVD1 heterogeneous correlation coefficient between Z500 and Pr-Circ shows a double-blocking anticyclone locating in the mid-latitudes. When Z500 presents a "-+-" tripole pattern, the WPSH moves easterly and southerly, under which the central of study area is controlled by the high-pressure system (Fig. 7a). Thus, PrCirc in most of study area except for Taklimakan Desert decreases significantly (Fig. 7c). When the distribution pattern of Z500 is similar to that in Fig. 7a and the northeasterly wind anomaly occurs at 850 $\mathrm{hPa}$ in North China, the water vapor transport from the low latitudes is reduced, which then suppresses the formation of $\operatorname{Pr}(\mathrm{Wu}$ and Zhang 2011). Compared with the SVD results before DA-CCA, it is found that the patterns of the key areas that affect the total Pr and Pr-Circ are significantly different (Fig. 5a and Fig. 7a), and the SCF of SVD1 increases from 30.75-53.01\%, implying that the DA-CCA method can effectively separate the influence of the atmospheric circulation on $\mathrm{Pr}$.

The distribution of the SVD1 heterogeneous correlation coefficient between SM and Pr-Res reveals the key region of SM-Pr feedback. When the soil is wet in the Mongolian Plateau and the Huanghuai area of China and dry in the Tibetan Plateau, the southeast and northeast China, the Pr-Res increases in most of the study region. Compared with the SVD results before $D A$, it is found that although the correlation and significance of the key areas of SM affecting total Pr and Pr-Res are weakened, the spatial pattern is consistent (Fig. 5b and Fig. 7b). There are significant differences in the key areas affected by SM (Fig. 5d and Fig. 7d), indicating that it is more effective to analyze the effect of SM on Pr_Res than that on Pr directly.

Figure 8 shows the mean, linear trend, and STD of Pr and its two components, Pr-Circ and Pr-Res for the period of 1980-2019 over Asian mid-low latitudes. The mean spatial pattern of Pr-Circ is similar to that of the original $\operatorname{Pr}$ (Fig. $8 \mathrm{a}$, accounting for $97.5 \%$ of the total mean Pr), while Z 2500 is similar to its circulation analog (figure not shown). The pattern of mean Pr-Res is also similar to that of total Pr, but the magnitude is much smaller (accounting for $2.5 \%$ of the total mean Pr). From the ratio of Pr-Circ to Pr, it can be seen that Pr-Cric dominates the magnitude and the spatial pattern of the JJA Pr and the circulation analog obtained through DA well reflects the average distribution of Z500 over Asian mid-low latitudes. 
The total Pr shows a weak increasing trend with the center in south of $30^{\circ} \mathrm{N}$, but it displays slightly decreasing trend in the Indian Peninsula and the middle and lower reaches of the Yangtze River basin (Fig. 1a). Pr-Res shows an increasing trend in most of the study region, while Pr-Circ mainly weakens (Figs. 8b, e). The strong increasing trend of total Pr in Indochina Peninsula mainly depends on Pr-Res, while the weakening trend in the Indian Peninsula and the middle and lower reaches of the Yangtze River basin is jointly contributed by Pr-Circ and Pr-Res (Fig. 1a, Figs. 8b and 8e). The 500hPa constructed circulation analog shows a weakening trend over the Northwest Pacific, consistent with the WPSH and an increasing trend in the mid-high latitudes and the Iranian Plateau, which is unfavorable for Pr-Circ in northern China and the Indian Peninsula (Fig. 8b). This result indicates that the northward movement of the WPSH is the main circulation driving factor, leading to Pr-Circ increasing in northeastern Asia and decreasing on the southeastern coast. The coefficient of determination (CD), defined as the square of the percentage of squared pattern correlation between component and total $\operatorname{Pr}\left(C D=100 \% * R^{2}\right)$, is adopted here to quantify the contribution of the two components to the total Pr trend (Wang et al. 2018). The CD of Pr-Res (88.15\%) is much higher than that of Pr-Circ (6.79\%), indicating that the Pr-Res dominates the trend of total Pr. The above analysis shows that Pr-Res can better explain the trend of total Pr after removing the effect of atmospheric circulation. That is, the Pr trend over Asian mid-low latitudes is mainly controlled by land surface factors, even though its magnitude is relatively small.

The STD represents the interannual variability of the JJA Pr in the past 40 years, and the land $\mathrm{Pr}$ components in south of the study region both present a wetter trend (Figs. 8c, f), similar to the total $\operatorname{Pr}(\mathrm{CDs}$ $>98 \%$ ). The significant increase in the STD of Pr-Res south of $30^{\circ} \mathrm{N}$ may be related to the larger variability in SM in the humid area than in the arid and semiarid areas in the northwestern area.

\subsection{Physical mechanism of Pr-Res trend}

The DA results clearly show the different impacts of both atmospheric circulation and land surface processes on Pr over Asian mid-low latitudes. SM-Pr feedback is achieved through ET, which modifies available water vapor within the planet boundary layer. Water vapor evaporating from soil is associated with the phase change of water (from liquid to gas), which alters the partition of $R_{\text {net }}$ between the LHF and SHF (GHF is omitted due to its small magnitude). That is, ET affects the distribution of land surface available energy ( $\left.R_{\text {net }}-G H F\right)$ between SHF and LHF, and this effect can be quantified by the evaporation fraction (EF) (Seneviratne et al. 2010),

$$
E F=\frac{L H F}{R_{n e t}-G H F} \approx \frac{L H F}{S H F+L H F}
$$

For different EF ranges, the dominant controlling factors on ET are also different so that the mechanisms of water vapor transport from land to the atmosphere are also different. When EF is in the range of $0 \sim 0.5$ (the red area in Fig. 9a), the available energy is mainly SHF. The corresponding area is called the "water-limited area", where the land is relatively dry and the $R_{\text {net }}$ is sufficient. When EF is in the range of $0.5 \sim 1$ (the blue area in Fig. 9a), most of the available energy is used for ET. This area is called the "energy-limited area", where ET is mainly determined by the available energy and the SM is sufficient. 
The spatial pattern of EF is quite similar to that of Pr-Res except for in the south of Tibetan Plateau, where high and complex topography exist (Figs. 8d and 9a). The increase in EF in the Tibetan Plateau, Indian Peninsula and southeast China indicates that more land surface available energy is contributed by LHF (Fig. 9b). EF is mainly decreasing in the north of $40^{\circ} \mathrm{N}$, where more available energy is consistent of SHF. The water vapor for Pr is mainly provided by the external transport of atmospheric advection and local land surface ET. Changes in the above two conditions reveal the physical mechanisms of land-atmosphere coupling on Pr from the perspective of water vapor sources. In addition, the spatial pattern of EF trend is similar to that of Pr-Res (Fig. 8h, r=0.29, a = 0.01), and the following analysis is conducted from the aspects of water and energy supply to EF. Here, the $0-40 \mathrm{~cm} \mathrm{SM}$ is used to characterize the soil water condition in the water-limited area, and the available energy trend is used in the energy-limited area.

In the water-limited area, a significant soil wetting trend appears in the belt-shaped region from the Tianshan Mountains to the Greater Hinggan Mountains and the north side of Tibetan Plateau (Fig. 9c), where the land surface conditions are conducive to the enhancement of SM-ET feedback. Under the global warming context, the land surface in Northwest China has become warmer and wetter in recent decades (Peng and Zhou 2017; Shi et al. 2007), and ET is mainly limited by SM. In the West Siberian Plain and the Gangetic plain, Pr-Res decreases significantly with the drying of SM, indicating their changes are in the same phase. However, in the periphery of the Tarim Basin where the soil shows wetting tendency, the variation trend of PrRes is relatively weak. This indicates that in the water-limited area, the sensitivity of Pr-Res to the SM reduction is stronger than that of SM enhancement. Central China and the Korean Peninsula are located in humid areas, where ET is limited by the available energy. In the energy-limited region, the Pr-Res decreases in eastern China but increase the Korean Peninsula and the Indian Peninsula, the pattern of which are consistent with the that of available energy (Figs. $8 \mathrm{e}$ and $9 \mathrm{~d}$ ). It is noted that the Mongolian Plateau is located in the transition area of $E F=0.4 \sim 0.6$, where the effects of enhancement in $\mathrm{SM}$ and reduction in available energy cancel each other, Pr-Res has a slightly strengthening trend. This means that the influence of land surface processes on $\mathrm{Pr}$ in the dry-wet transition region is very complex and deserved further research in future work. Besides, we have distinguished the contribution of large-scale transport and local ET from the perspective of water vapor sources in this study. However, the indirect influence of SM on Pr through regulating circulation is not discussed (Conil et al. 2007; Zeng and Yuan 2021), which can be addressed through the numerical experiments by using climate models in the future. The definition of EF depends on SM, while the land surface energy balance is also affected by other factors. Study found that the intense melting of snow in west Russia and Siberia in April and May had a strong impact on the SHF, PBLH and Pr in the next month (Ye and Lau 2019).

\section{Summary}

In this study, DA-CCA approach was used to quantitatively separate the contributions of atmospheric circulation and local ET to summer Pr over Asian mid-low latitudes. First, the DA-CCA approach was applied to identify the contribution of atmospheric circulation to summer $\operatorname{Pr}$ (i.e., Pr-Circ), and then Pr-Res was defined as the contribution of the land-atmosphere coupling. Z500 was used to describe the effect of atmospheric circulation, and SM was used to represent the land surface condition. Then, the influence and 
physical mechanisms of land-atmosphere coupling on Pr were also analyzed. Our major conclusions are as follows:

1. After removing the effect of atmospheric circulation, Pr-Res represents the part of the JJA Pr over Asian mid-low latitudes inducted by local ET resulted from land surface processes.

2. The key Z500 pattern affecting summer Pr over Asian mid-low latitudes is the zonal tripole in the midlatitude after separating the effects of atmospheric circulation through DA-CAA.

3. Although Pr-Res is small in magnitude, it dominates the trend pattern of the total JJA Prover Asian midlow latitudes in the past 40 years. This understanding may provide information for improving regional summer climate prediction.

4. The soil wetting trend in the land water-limited areas in study regions explain the enhancement of PrRes in the corresponding region to a certain extent and it play dominant role on total Pr trend.

The attribution analysis of land Pr based on the DA-CCA approach is essentially important to summer climate prediction over Asian mid-low latitudes. Considering the dominant role of summer Pr in the monsoon region throughout the year, this study mainly analyzes the period from June to August. The situation of other seasons may be analyzed and discussed in similar way further studies. In addition, the subregions divided by EF over Asian mid-low latitudes cannot clearly explain the Pr trend in the wet-dry transition zone, which is the hotspot of land-atmosphere coupling (Koster et al. 2004). Above issues are relevant to the land-atmosphere coupling mechanism in this region, which should be well explored in the future.

\section{Declarations}

Statements \& Declarations

This research was jointly supportedby the National Natural Science Fund for Distinguished Young Scholars (Grant No. 41925021) and the National Natural Science Foundation of China (Grant No. 41875106).The authors have no relevant financial or non-financial interests to disclose.

Author Contributions

All authors contributed to the study conception and design. Material preparation, data collection and analysis were performed by Yue Chen. The first draft of the manuscript was written by Yue Chen and Aihui Wang and all authors commented on previous versions of the manuscript. All authors read and approved the final manuscript.

Data Availability

The datasets generated during and/or analysed during the current study are not publicly available due to part of the dataset is still needed in the author's dissertation, but are available from the corresponding author on reasonable request. 


\section{References}

1. Aizen, E., V. Aizen, J. Melack, T. Nakamura, and T. Ohta(2001) Precipitation and atmospheric circulation patterns at Mid-Latitudes of Asia. Int J Climatol., 21, 535-556.

2. Barnett, T. P., L. D?menil, U. Schlese, E. Roeckner, and M. Latif(1989) The effect of Eurasian snow cover on regional and global climate variations. J. Atmos. Sci., 46, 661-686.

3. Beaudoing, H., and M. Rodell 2019: GLDAS Noah Land Surface Model L4 monthly 1.0 x 1.0 degree V2.0. NASA/GSFC/HSL, Ed.

4. -- 2020: GLDAS Noah Land Surface Model L4 monthly 1.0 x 1.0 degree V2.1. NASA/GSFC/HSL, Ed.

5. Conil, S., H. Douville, and S. Tyteca(2007) The relative influence of soil moisture and SST in climate predictability explored within ensembles of AMIP type experiments. Clim. Dyn., 28, 125-145.

6. Deser, C., L. Terray, and A. S. Phillips(2016) Forced and internal components of winter air temperature trends over North America during the past 50 Years: Mechanisms and implications. J. Climate, 29, 2237-2258.

7. Ding, Y., and J. C. L. Chan(2005) The East Asian summer monsoon: an overview. Meteorol. Atmos. Phys., 89, 117-142.

8. Ek, M. B., and A. A. M. Holtslag(2004) Influence of soil moisture on boundary layer cloud development. J. Hydrometeor., 5, 86-99.

9. Eltahir, E. A. B., and R. L. Bras(1996) Precipitation recycling. Rev. Geophys., 34, 367-378.

10. Goddard, L., S. J. Mason, S. E. Zebiak, C. F. Ropelewski, R. Basher, and M. A. Cane(2001) Current approaches to seasonal to interannual climate predictions. Int J Climatol., 21, 1111-1152.

11. Guo, Z., P. Dirmeyer, R. Koster et al (2006) GLACE: the global land-atmosphere coupling experiment. Part II: analysis. J. Hydrometeor., 7.

12. Hersbach, H., B. Bell, P. Berrisford et al (2020) The ERA5 global reanalysis. Q. J. R. Meteorol. Soc., 146, 1999-2049.

13. Huang, R., J. Chen, L. Wang, and Z. Lin(2012) Characteristics, processes, and causes of the spatiotemporal variabilities of the East Asian monsoon system. Acta Meteorol. Sin., 29, 910-942.

14. Hurrell, J. W.(1995) Decadal trends in the north atlantic oscillation: Regional temperatures and precipitation. Science, 269, 676-679.

15. Jones, A. R., and N. A. Brunsell(2009) A scaling analysis of soil moisture-precipitation interactions in a regional climate model. Theor App/ Climatol, 98, 221-235.

16. Koster, R., P. Dirmeyer, Z. Guo et al (2004) Regions of strong coupling between soil moisture and precipitation. Science, 305, 1138-1140.

17. Koster, R., Z. Guo, P. Dirmeyer et al (2006) GLACE: The Global Land-Atmosphere Coupling Experiment. Part l: overview. J. Hydrometeor., 7.

18. Koster, R. D., S. P. P. Mahanama, T. J. Yamada et al (2011) The second phase of the Global LandAtmosphere Coupling Experiment: Soil moisture contributions to subseasonal forecast skill. J. Hvdrometeor. 12.805-822

Loading [MathJax]/jax/output/CommonHTML/fonts/TeX/fontdata.js

Page 13/23 
19. Liu, L., R. Zhang, and Z. Zuo(2017) Effect of spring precipitation on summer precipitation in Eastern China: role of soil moisture. J. Climate, 9183-9194.

20. Lorenz, E.(1969) Atmospheric predictability as revealed by naturally occurring analogues. J. Atmos. Sci., $26,636-646$.

21. Meehl, G. A., and J. M. Arblaster(2001) The tropospheric biennial oscillation and Indian monsoon rainfall. Geophys. Res. Lett., 28, 1731-1734.

22. Merrifield, A., F. Lehner, S.-P. Xie, and C. Deser(2017) Removing circulation effects to assess central U.S. land-atmosphere interactions in the CESM Large Ensemble. Geophys. Res. Lett., 44, 9938-9946.

23. Nicolai-Shaw, N., L. Gudmundsson, M. Hirschi, and S. Seneviratne(2016) Long-term predictability of soil moisture dynamics at the global scale: Persistence versus large-scale drivers. Geophys. Res. Lett.

24. Orth, R., and S. Seneviratne(2016) Variability of soil moisture and sea surface temperatures similarly important for warm-season land climate in the Community Earth System Model. J. Climate, 30.

25. Peng, D., and T. Zhou(2017) Why was the arid and semiarid northwest China getting wetter in the recent decades? J. Geophys. Res.: Atmos., 122, 9060-9075.

26. Prohaska, J.(1976) A technique for analyzing the linear relationships between two meteorological fields. Mon. Wea. Rev., 104.

27. Qi, W., J. Liu, and D. Chen(2018) Evaluations and improvements of GLDAS2.0 and GLDAS2.1 forcing data's applicability for basin scale hydrological simulations in the Tibetan Plateau. J. Geophys. Res.: Atmos., 123, 13,128-113,148.

28. Qi, W., J. Liu, H. Yang et al (2020) Large uncertainties in runoff estimations of GLDAS versions 2.0 and 2.1 in China. Earth Space Sci., 7.

29. Rohrer, M., O. Martius, C. C. Raible, and S. Brönnimann(2020) Sensitivity of blocks and cyclones in ERA5 to spatial resolution and definition. Geophys. Res. Lett., 47, e2019GL085582.

30. Saffioti, C., E. M. Fischer, S. C. Scherrer, and R. Knutti(2016) Reconciling observed and modeled temperature and precipitation trends over Europe by adjusting for circulation variability. Geophys. Res. Lett., 43, 8189-8198.

31. Seneviratne, S. I., T. Corti, E. L. Davin et al (2010) Investigating soil moisture-climate interactions in a changing climate: A review. Earth-Sci. Rev., 99, 125-161.

32. Seo, E., M.-I. Lee, J.-H. Jeong et al (2019) Impact of soil moisture initialization on boreal summer subseasonal forecasts: mid-latitude surface air temperature and heat wave events. Clim. Dyn., 52, 16951709.

33. Shi, Y., Y. Shen, E. Kang, D. Li, Y. Ding, G. Zhang, and R. Hu(2007) Recent and future climate change in Northwest China. Clim. Change, 80, 379-393.

34. Shukla, J., and Y. Mintz(1982) Influence of land-surface evapotranspiration on the earth's climate. Science, 215, 1498-1501.

35. Smoliak, B. V., J. M. Wallace, P. Lin, and Q. Fu(2015) Dynamical adjustment of the Northern Hemisphere surface air temperature field: Methodology and application to observations. J. Climate, 28, 1613-1629. 
36. Taylor, C. M., A. Gounou, F. Guichard, P. P. Harris, R. J. Ellis, F. Couvreux, and M. De Kauwe(2011) Frequency of Sahelian storm initiation enhanced over mesoscale soil-moisture patterns. Nat. Geosci., 4, 430-433.

37. Trenberth, K. E., G. W. Branstator, D. Karoly, A. Kumar, N.-C. Lau, and C. Ropelewski(1998) Progress during TOGA in understanding and modeling global teleconnections associated with tropical sea surface temperatures. J. Geophys. Res.: Oceans, 103, 14291-14324.

38. Wallace, J., C. Smith, and C. Bretherton(1992) Singular value decomposition of wintertime sea surface temperature and 500-mb height anomalies. J. Climate, 5, 561-576.

39. Wallace, J., Q. Fu, B. Smoliak, P. Lin, and C. Johanson(2012) Simulated versus observed patterns of warming over the extratropical Northern Hemisphere continents during the cold season. Proc. Natl. Acad. Sci. U. S. A., 109, 14337-14342.

40. Wang, A., L. Xu, and X. Kong(2018) Assessments of the Northern Hemisphere snow cover response to 1.5 and $2.0^{\circ} \mathrm{C}$ warming. Earth Syst. Dynam., 9, 865-877.

41. Wang, W., W. Cui, X. Wang, and X. Chen(2016) Evaluation of GLDAS-1 and GLDAS-2 forcing data and Noah model simulations over China at monthly scale. J. Hydrometeor., 17.

42. Wu, B., and R. Zhang(2011) Interannual variability of the East Asian summer monsoon and its association with the anomalous atmospheric circulation over the mid-high latitudes and external forcing (in Chinese). Acta Meteorol. Sin., 69, 219-233.

43. Wu, Z., X. Li, Y. Li, and Y. Li(2016) Potential Influence of Arctic Sea Ice to the Interannual Variations of East Asian Spring Precipitation. J. Climate, 29, 2797-2813.

44. Yang, K., and C. Wang(2019) Seasonal persistence of soil moisture anomalies related to freeze-thaw over the Tibetan Plateau and prediction signal of summer precipitation in eastern China. Clim. Dyn., 53.

45. Yang, Y., R. J. Donohue, and T. R. McVicar(2016) Global estimation of effective plant rooting depth: Implications for hydrological modeling. Water Resour. Res., 52, 8260-8276.

46. Ye, K., and N.-C. Lau(2019) Characteristics of Eurasian snowmelt and its impacts on the land surface and surface climate. Clim. Dyn., 52, 1115-1138.

47. Zeng, D., and X. Yuan(2021) Modeling the influence of upstream land-atmosphere coupling on the 2017 persistent drought over Northeast China. J. Climate, 34, 4971-4988.

48. Zhang, R.(2015) Changes in East Asian summer monsoon and summer rainfall over eastern China during recent decades. Chin. Sci. Bull., 60, 1222-1224.

\section{Tables}

Tab.1 The linear trend of the JJA mean variables from GLDAS-2.0and GLDAS-2.1 during the overlapping period (2000-2014) and from merged GLDAS during the whole study period (1980-2019) over Asian mid-low latitudes 


\begin{tabular}{|llll|}
\hline Variables (unit) & \multicolumn{2}{l|}{ Overlapping Period(2000-2014) } & $1980-2019$ \\
\cline { 2 - 3 } & GLDAS-2.0 & GLDAS-2.1 & GLDAS-Merged \\
\hline $\operatorname{Pr}(\mathrm{mm} / \mathrm{a})$ & 1.27 & 5.29 & 1.78 \\
\hline $0-40 \mathrm{~cm} \mathrm{SM}\left(\mathrm{m}^{3} / \mathrm{m}^{3} / \mathrm{a}\right)$ & 0.10 & 0.11 & $1.05 \mathrm{E}-03$ \\
\hline $\mathrm{LW}_{\text {net }}\left(\mathrm{W} / \mathrm{m}^{2} / \mathrm{a}\right)$ & 11.39 & 84.17 & -3.46 \\
\hline $\mathrm{SW}_{\text {net }}\left(\mathrm{W} / \mathrm{m}^{2} / \mathrm{a}\right)$ & -32.55 & 2.07 & 51.00 \\
\hline $\mathrm{LHF}\left(\mathrm{W} / \mathrm{m}^{2} / \mathrm{a}\right)$ & 49.48 & 41.52 & 38.17 \\
\hline $\mathrm{SHF}\left(\mathrm{W} / \mathrm{m}^{2} / \mathrm{a}\right)$ & -65.77 & 36.65 & 7.69 \\
\hline $\mathrm{GHF}\left(\mathrm{W} / \mathrm{m}^{2} / \mathrm{a}\right)$ & -4.94 & 5.14 & 1.62 \\
\hline
\end{tabular}

\section{Figures}
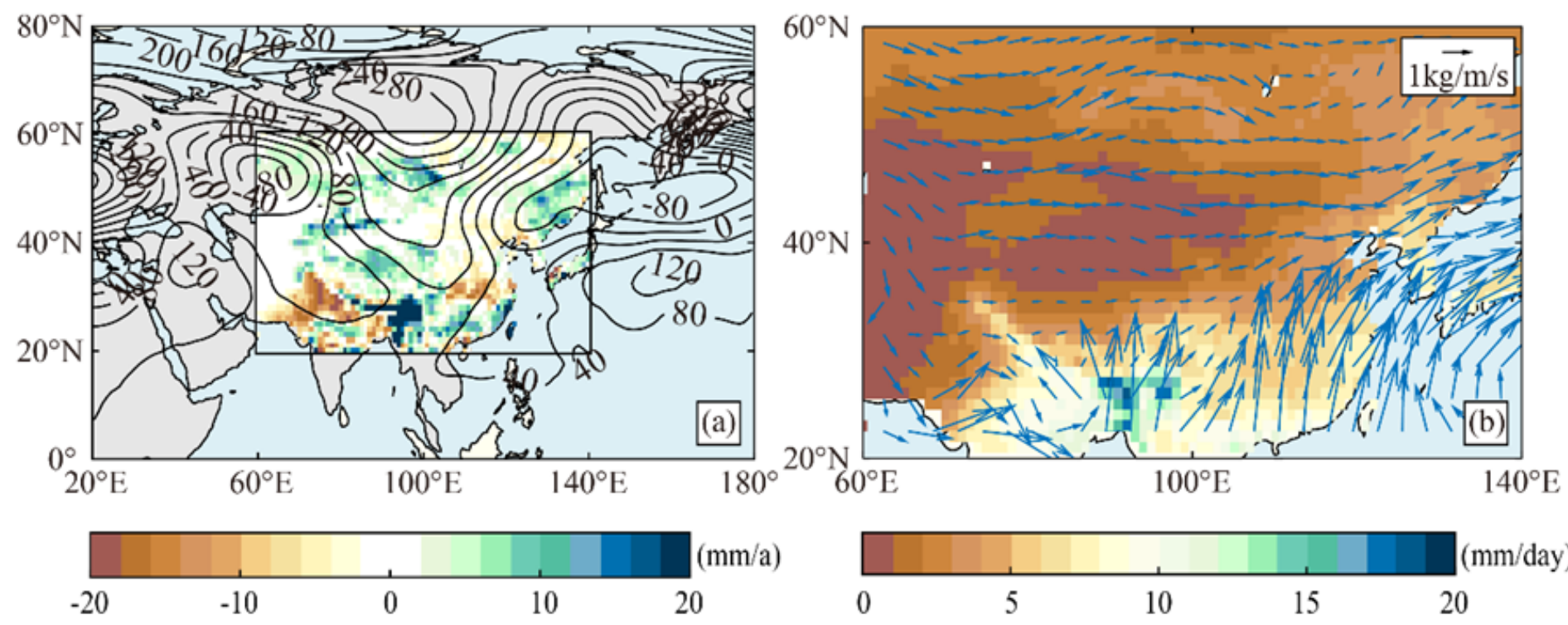

\section{Figure 1}

a Annual trends of the JJA Pr (color shading; mm/a) over Asian mid-low latitudes (black rectangular box: $20^{\circ}-60^{\circ} \mathrm{N}, 60^{\circ}-140^{\circ} \mathrm{E}$ ) and $\mathrm{Z} 500$ (contours; gpm/a) in the Northern Hemisphere $\left(0^{\circ}-80^{\circ} \mathrm{N}, 20^{\circ}-180^{\circ} \mathrm{E}\right.$ ) and $\mathrm{b}$ climatology mean of JJA $\operatorname{Pr}$ (color shading; $\mathrm{mm} /$ day) and vertical integral of horizonal water vapor fluxes (vectors; $\mathrm{kg} / \mathrm{m} / \mathrm{s}$ ) over Asian mid-low latitudes for the period of 1980-2019 


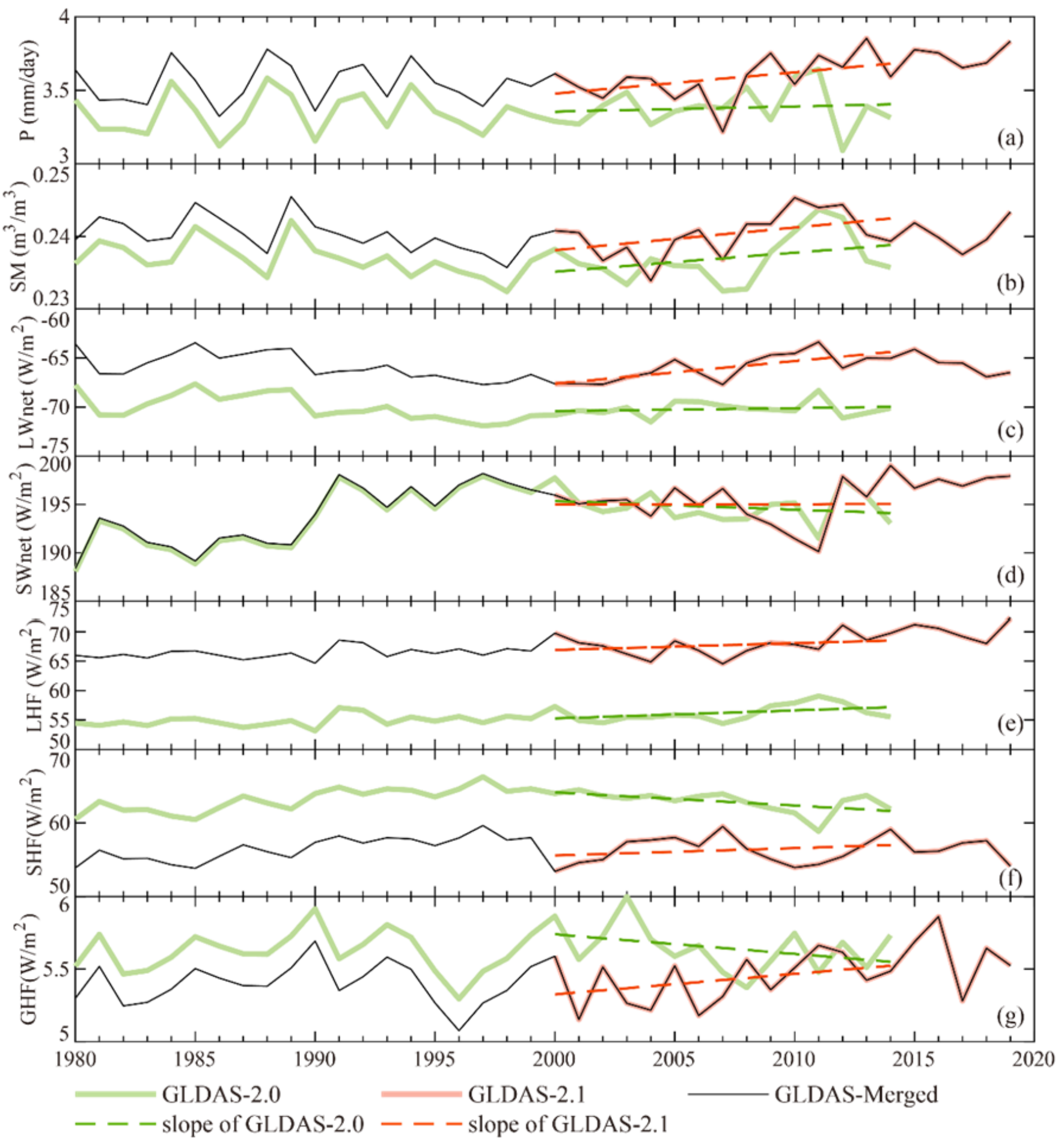

\section{Figure 2}

Annual time series and trend of the JJA mean a land $\operatorname{Pr}(\mathrm{mm} /$ day), b 0-10 cm SM (m3/m3), c LWnet $(\mathrm{W} / \mathrm{m} 2)$, d SWnet (W/m2), e LHF (W/m2), f SHF (W/m2) and g GHF (W/m2) from GLDAS-2.0 (green solid and dashed lines) and GLDAS-2.1 (orange solid and dashed lines) over Asian mid-low latitudes. The black solid lines are the series of merged GLDAS variables, and the dashed lines are trends during overlapping period (2000-2014) of GLDAS-2.0 and GLDAS-2.1. The available data periods are 1980-2014 for GLDAS-2.0 
(a) $\operatorname{Pr}(\mathrm{mm} /$ day $)$

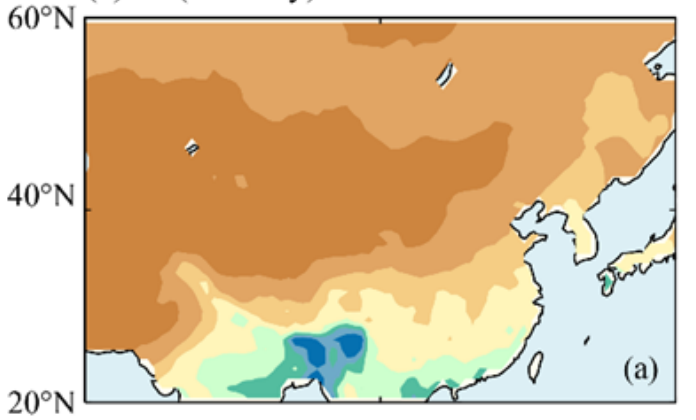

(c) LWnet $\left(\mathrm{W} / \mathrm{m}^{2}\right)$

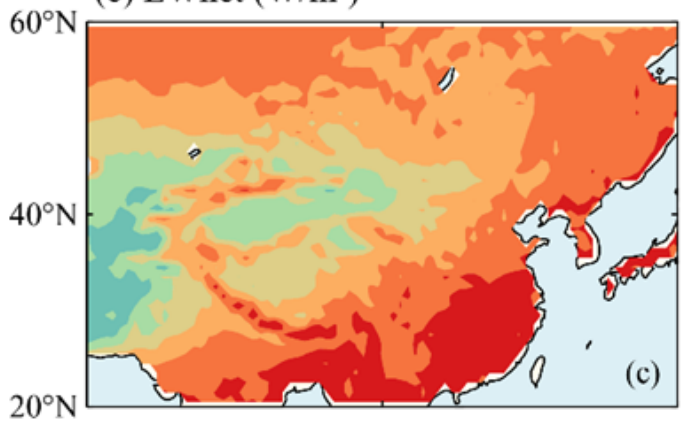

(e) $\mathrm{LHF}\left(\mathrm{W} / \mathrm{m}^{2}\right)$
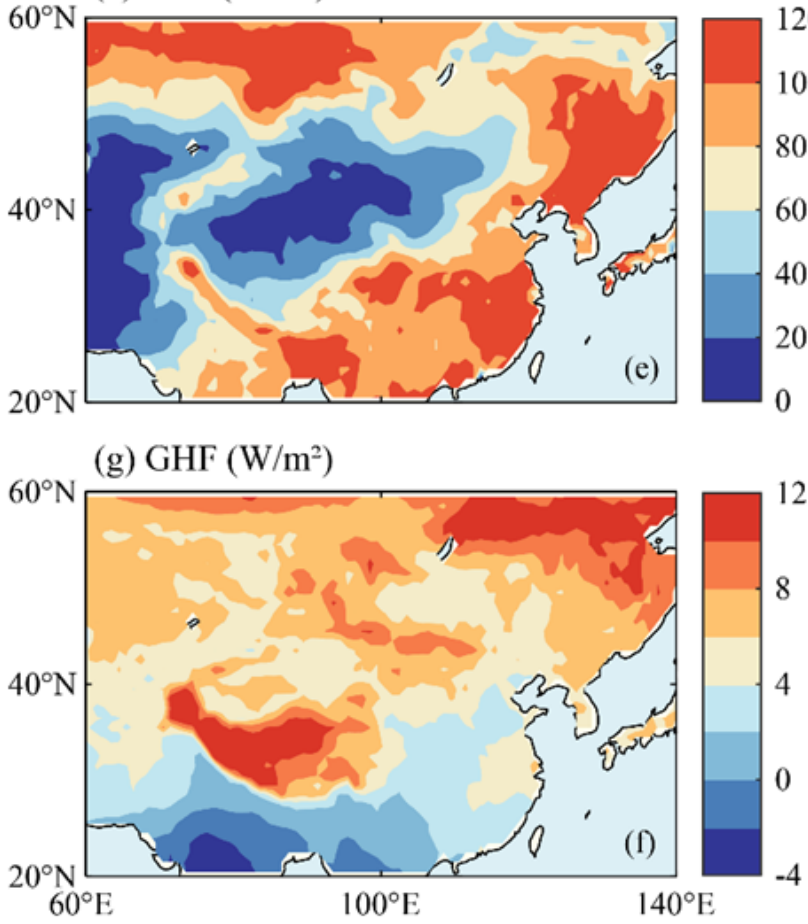

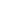

(b) $0-40 \mathrm{~cm} \mathrm{SM}\left(\mathrm{m}^{3} / \mathrm{m}^{3}\right)$

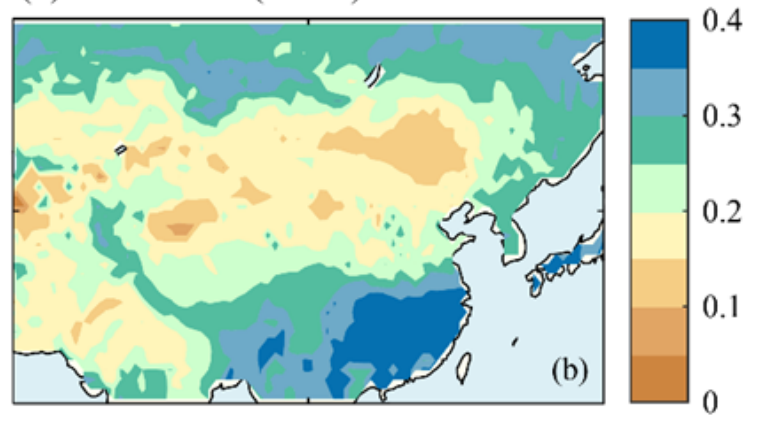

(d) SWnet $\left(\mathrm{W} / \mathrm{m}^{2}\right)$

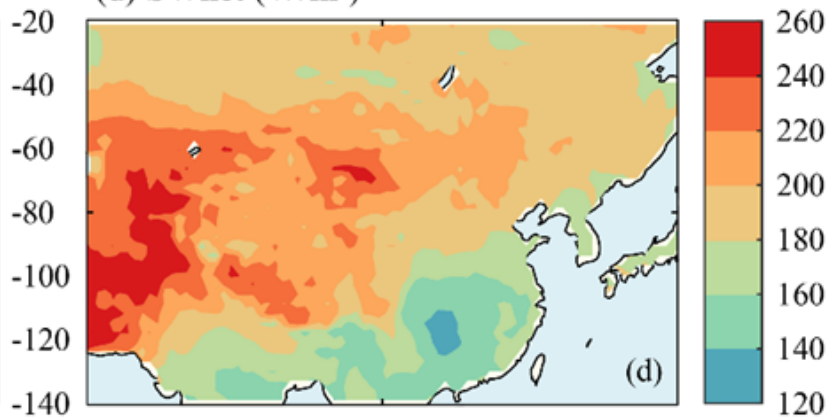

(f) $\mathrm{SHF}\left(\mathrm{W} / \mathrm{m}^{2}\right)$

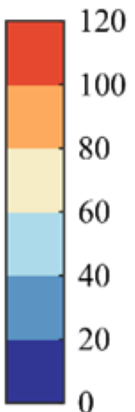

$60^{\circ} \mathrm{E}$

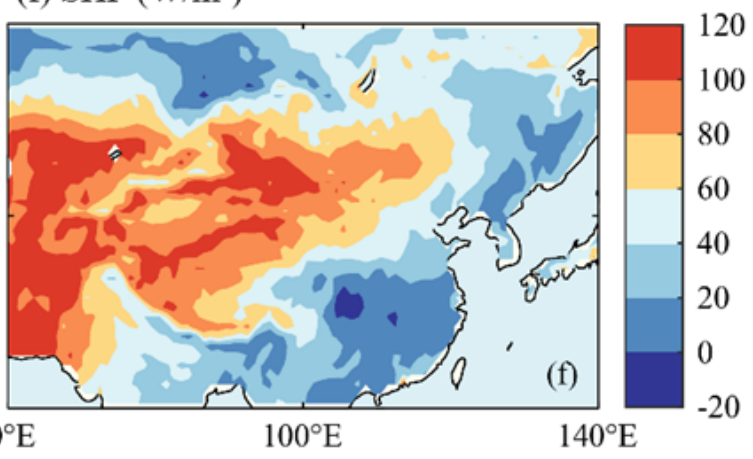

Figure 3

Climatology JJA mean (1980-2019) of a land $\operatorname{Pr}$ (mm/day), c LWnet (W/m2), d SWnet (W/m2), e LHF $(\mathrm{W} / \mathrm{m} 2), \mathrm{f}$ SHF $(\mathrm{W} / \mathrm{m} 2)$, and $\mathrm{g}$ GHF $(\mathrm{W} / \mathrm{m} 2)$ and b MJJ 0-10 $\mathrm{cm} \mathrm{SM}(\mathrm{m} 3 / \mathrm{m} 3)$ from the merged GLDAS dataset over Asian mid-low latitudes 


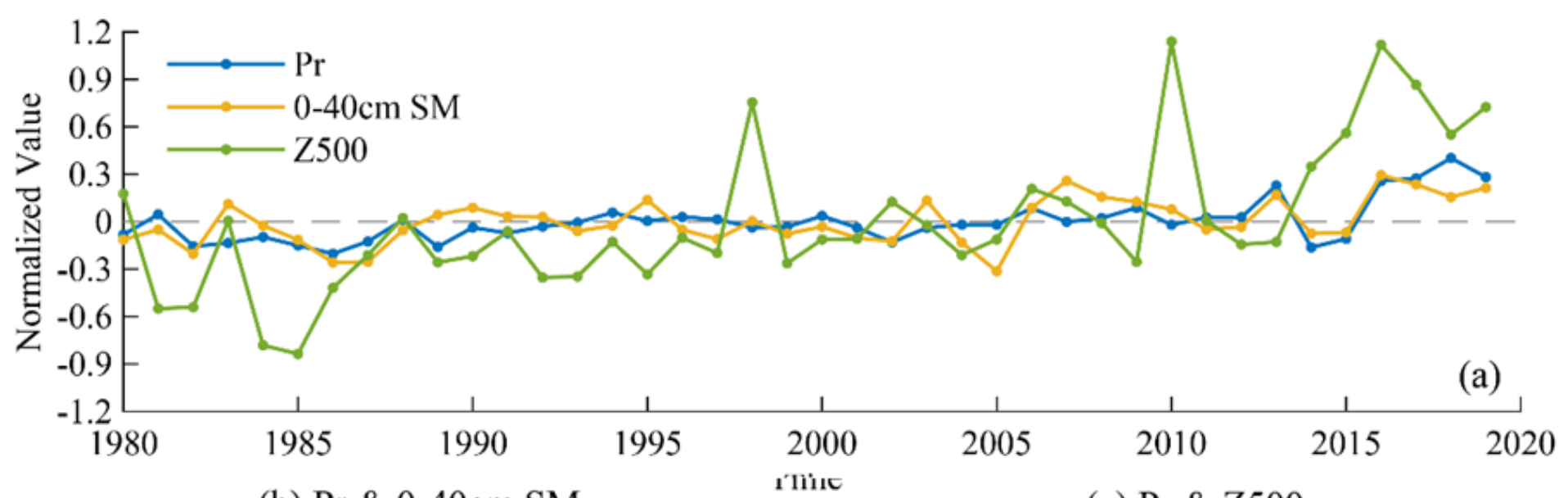

(b) $\operatorname{Pr} \& 0-40 \mathrm{~cm} \mathrm{SM}$
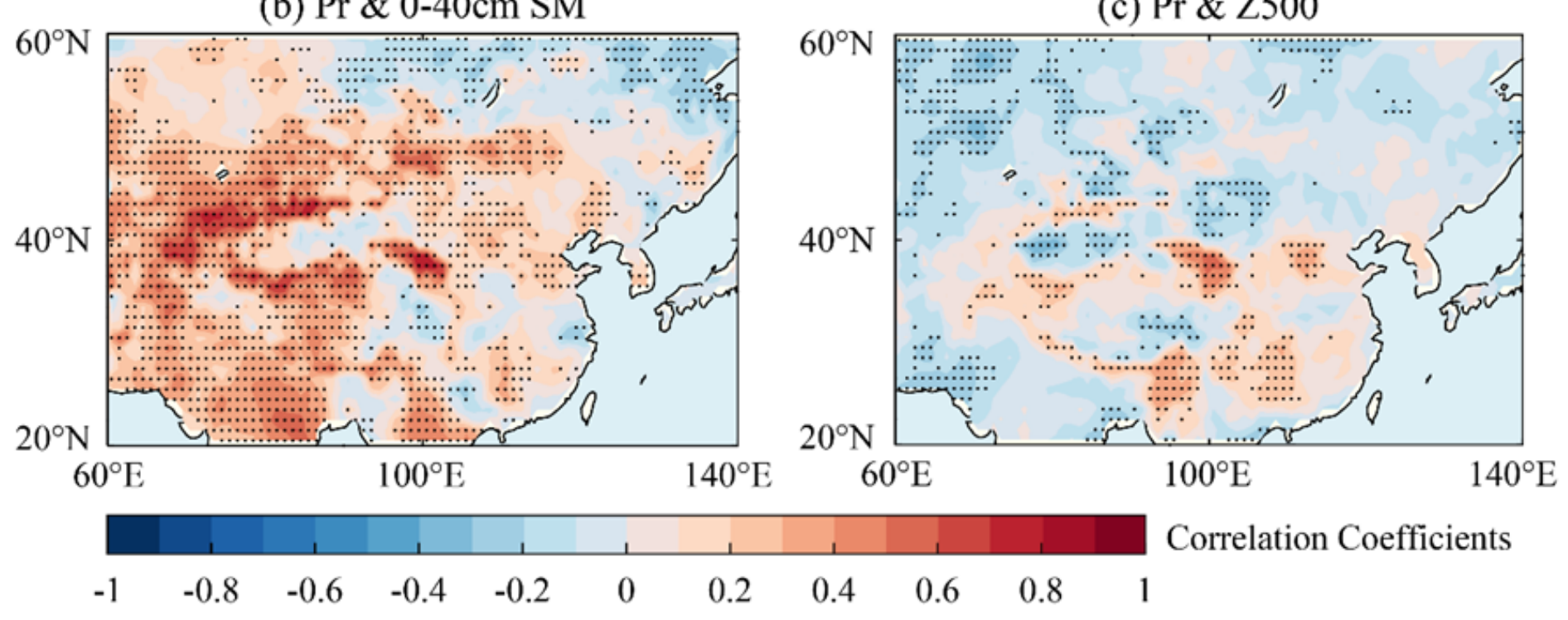

(c) $\operatorname{Pr} \& \mathrm{Z} 500$

Figure 4

a Temporal changes in area-averaged normalized JJA Pr, Z500 and MJJ 0-40 cm SM over Asian mid-low latitudes. The spatial distribution of the temporal correlation coefficients between the JJA Pr and b 0-40 cm $\mathrm{SM}$ and c Z500. The normalization of each variable and data preprocessing are described in Section 2.3. The dotted areas are statistically significant at the $5 \%$ level 

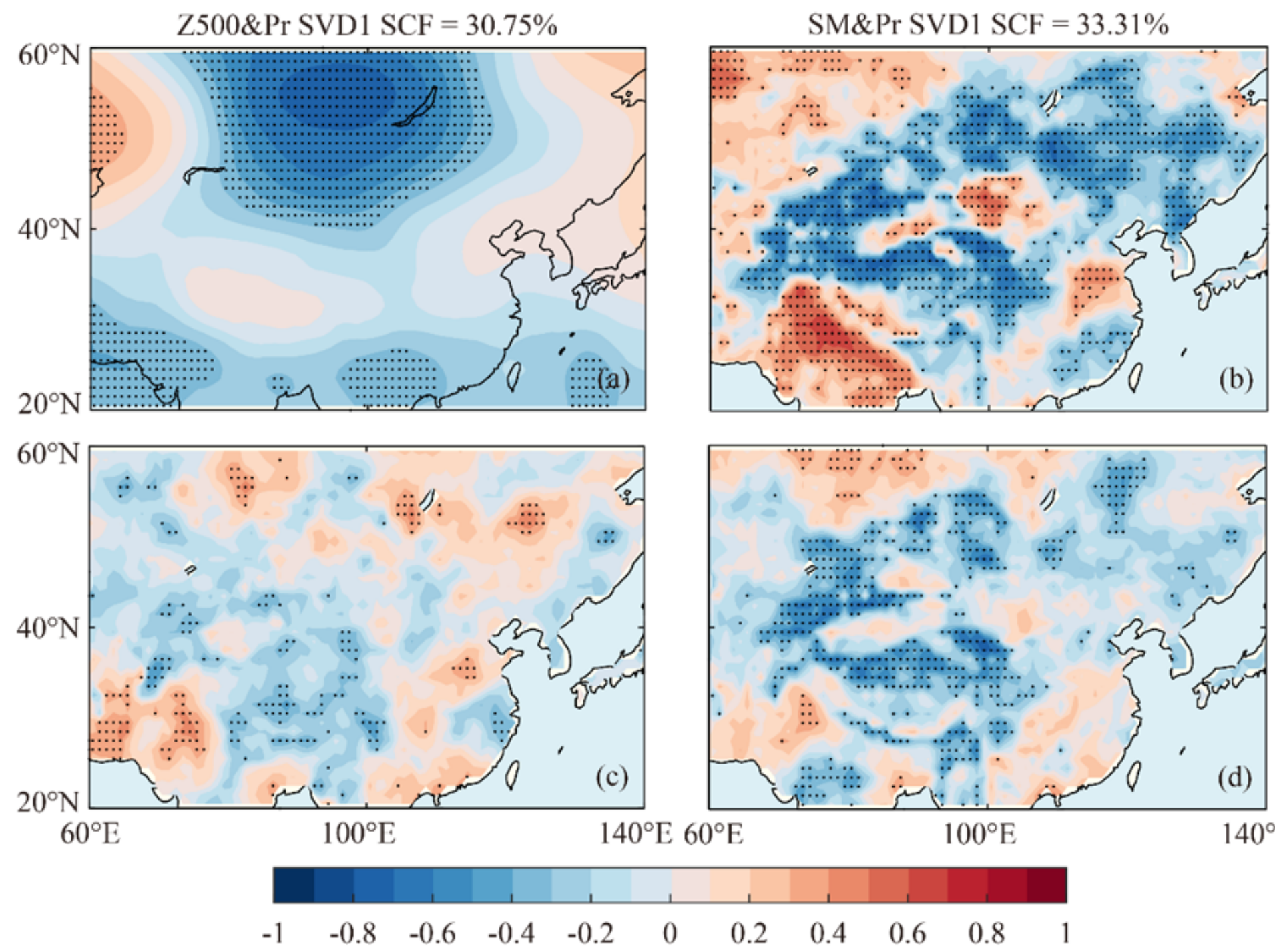

\section{Figure 5}

The heterogeneous correlation coefficients of the first SVD modes a,c between the JJA mean Z500 and Pr and b,d between the SM in the antecedent month and Pr over Asian mid-low latitudes from 1980-2019. The dotted areas are statistically significant at the $5 \%$ level
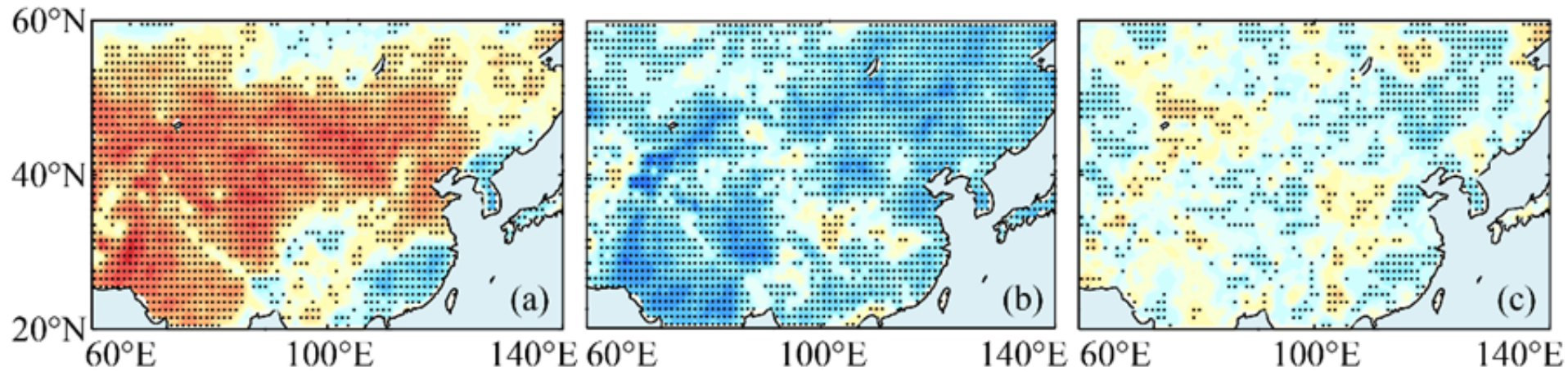

Correlation with Pr-Res

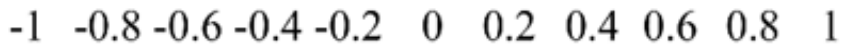


Correlations (color shading) between the JJA Pr-Res obtained using DA and a LHF, b SHF, and c PBLH over Asian mid-low latitudes from 1980 to 2019 . The dotted areas are statistically significant at the $5 \%$ level

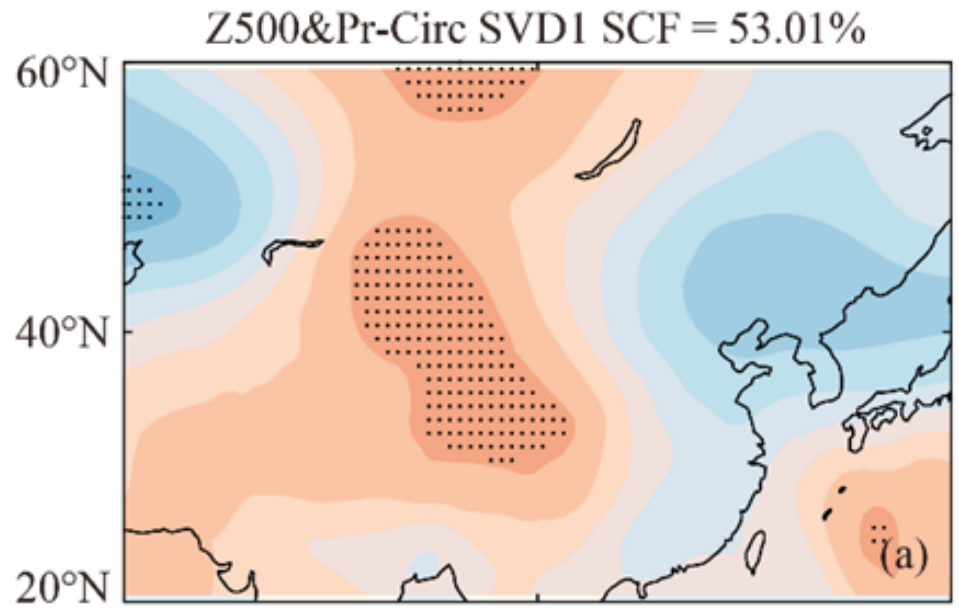

SM\&Pr-Res SVD1 SCF $=43.32 \%$

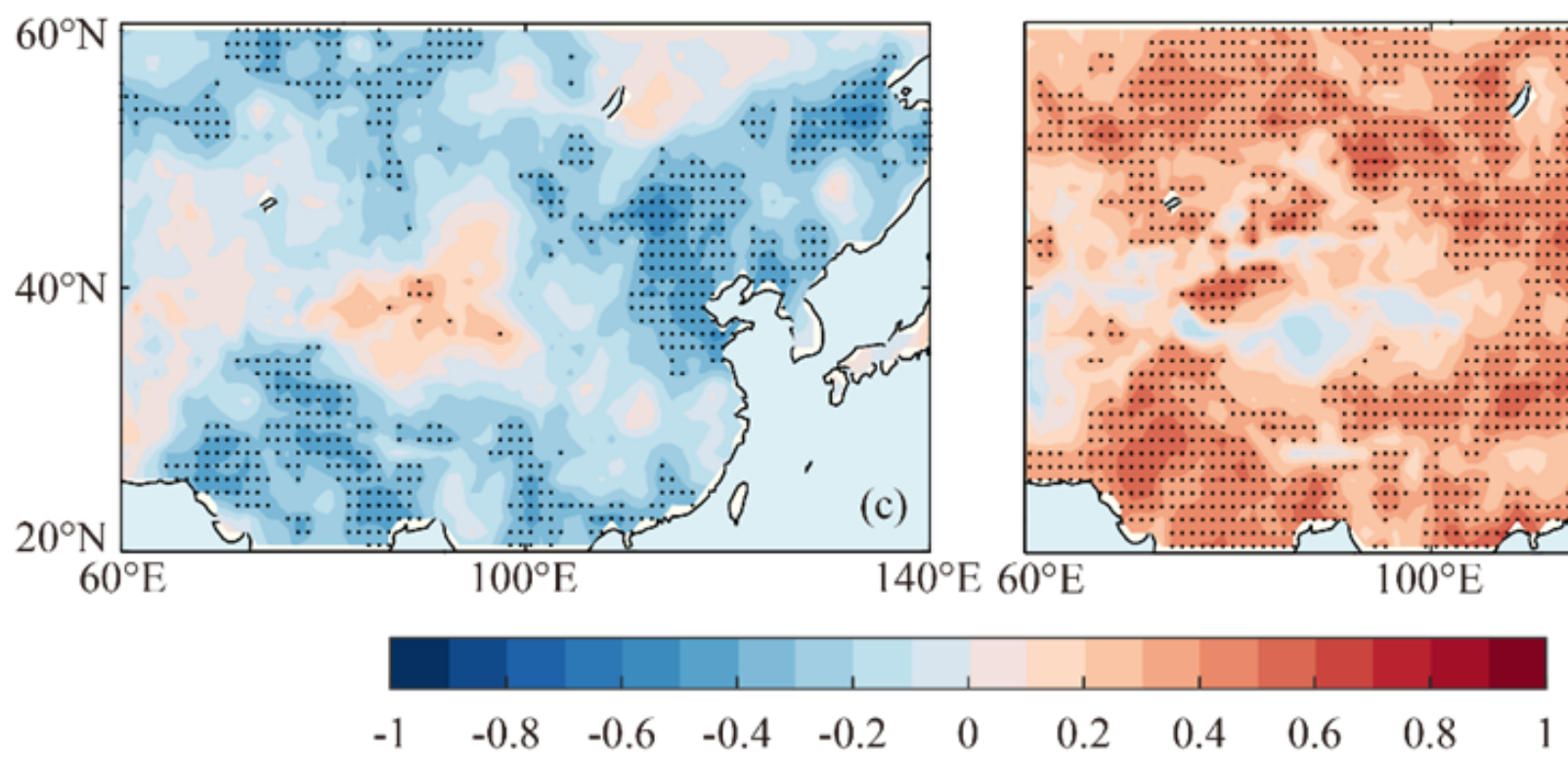

\section{Figure 7}

Similar to Figure 5, but for the heterogeneous correlation coefficients of the first SVD modes a,c between the JJA mean Z500 and Pr-Circ and b,d between 0-40 cm SM one month in advance and Pr-Res. The dotted areas are statistically significant at the $5 \%$ level 
(a) Pr-Circ Mean

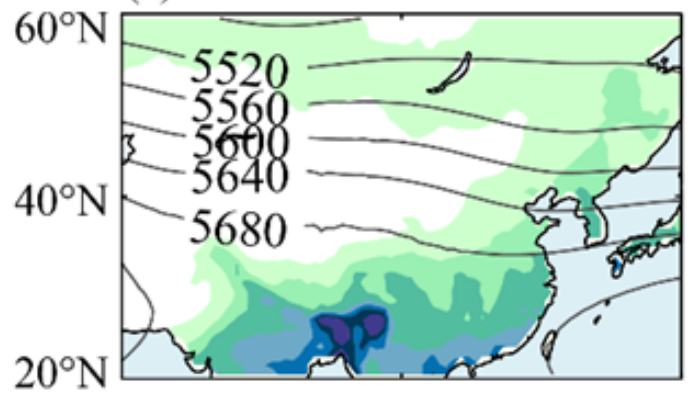

$60^{\circ} \mathrm{E}$

$100^{\circ} \mathrm{E}$ (b) Pr-Circ Trend

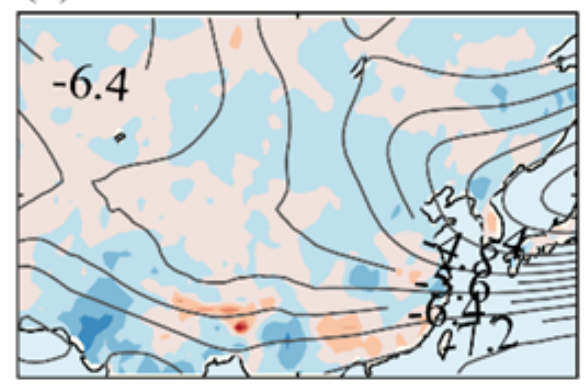

(c) Pr-Circ STD $\quad \mathrm{CD}=98.43 \%$

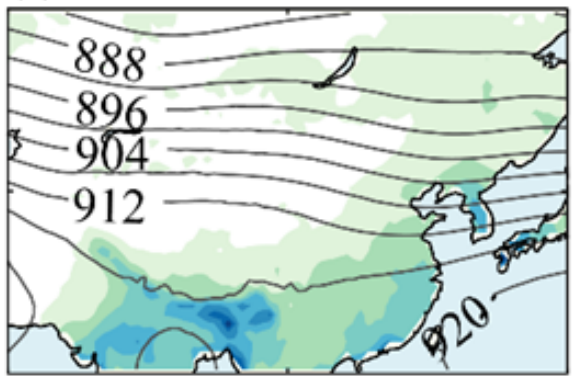

$100^{\circ} \mathrm{E}$

$140^{\circ} \mathrm{E}$
0
$\begin{array}{ll}4 & 8\end{array}$
$12 \quad 16 \quad-0.08 \quad-0.04$
$0.04 \quad 0.08$
$0 \quad 2$
4
68

(d) Pr-Res Mean

$2.50 \%$

(e) Pr-Res Trend $C D=88.15 \%$

(f) Pr-Res STD $\quad \mathrm{CD}=99.00 \%$
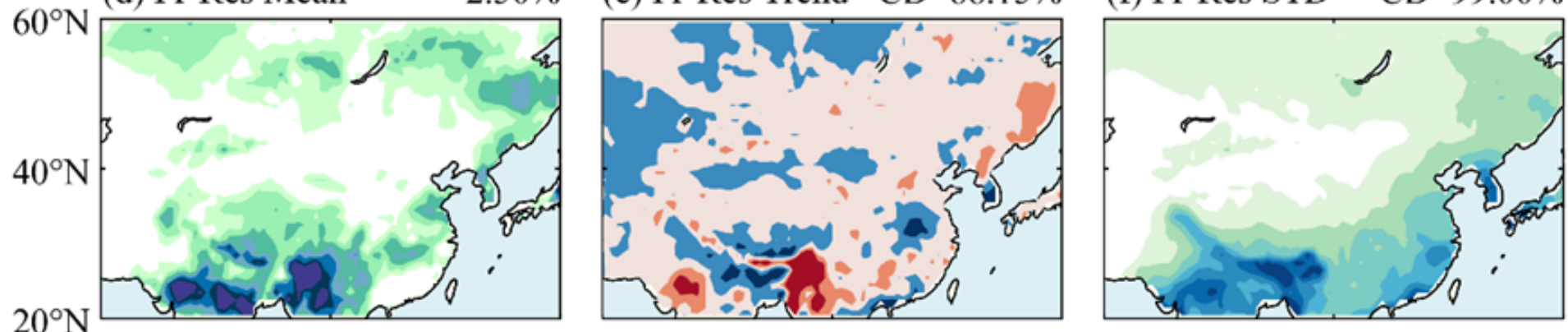

$60^{\circ} \mathrm{E}$

$100^{\circ} \mathrm{E}$

$140^{\circ} \mathrm{E} 60^{\circ} \mathrm{E}$

$100^{\circ} \mathrm{E}$

$140^{\circ} \mathrm{E} 60^{\circ} \mathrm{E}$

$100^{\circ} \mathrm{E}$

$140^{\circ} \mathrm{E}$

0

0.1

0.2

0.3

$\begin{array}{lll}0.4 & -0.08 & -0.04\end{array}$

$0.04 \quad 0.08$

0

2

4

$6 \quad 8$

Figure 8

a Climatological mean, $b$ trend and c STD of JJA Pr-Circ (color shading; mm/day, and the unit for trend value is $\mathrm{mm} / \mathrm{a}$ ) and constructed circulation analog (contour; gpm) over Asian mid-low latitudes. Panels in d, $e, f$ are same as those in $a, b, c$ but for Pr-Res (color shading; $\mathrm{mm} /$ day). The number marked in the upper right corner of $a$, $d$ represents the percentage of Pr-Circ and Pr-Res to the mean of total Pr, and those of b, c, $e, f$ are CDs of the trend and STD between Pr-Circ and Pr-Res and the total Pr for the study area 

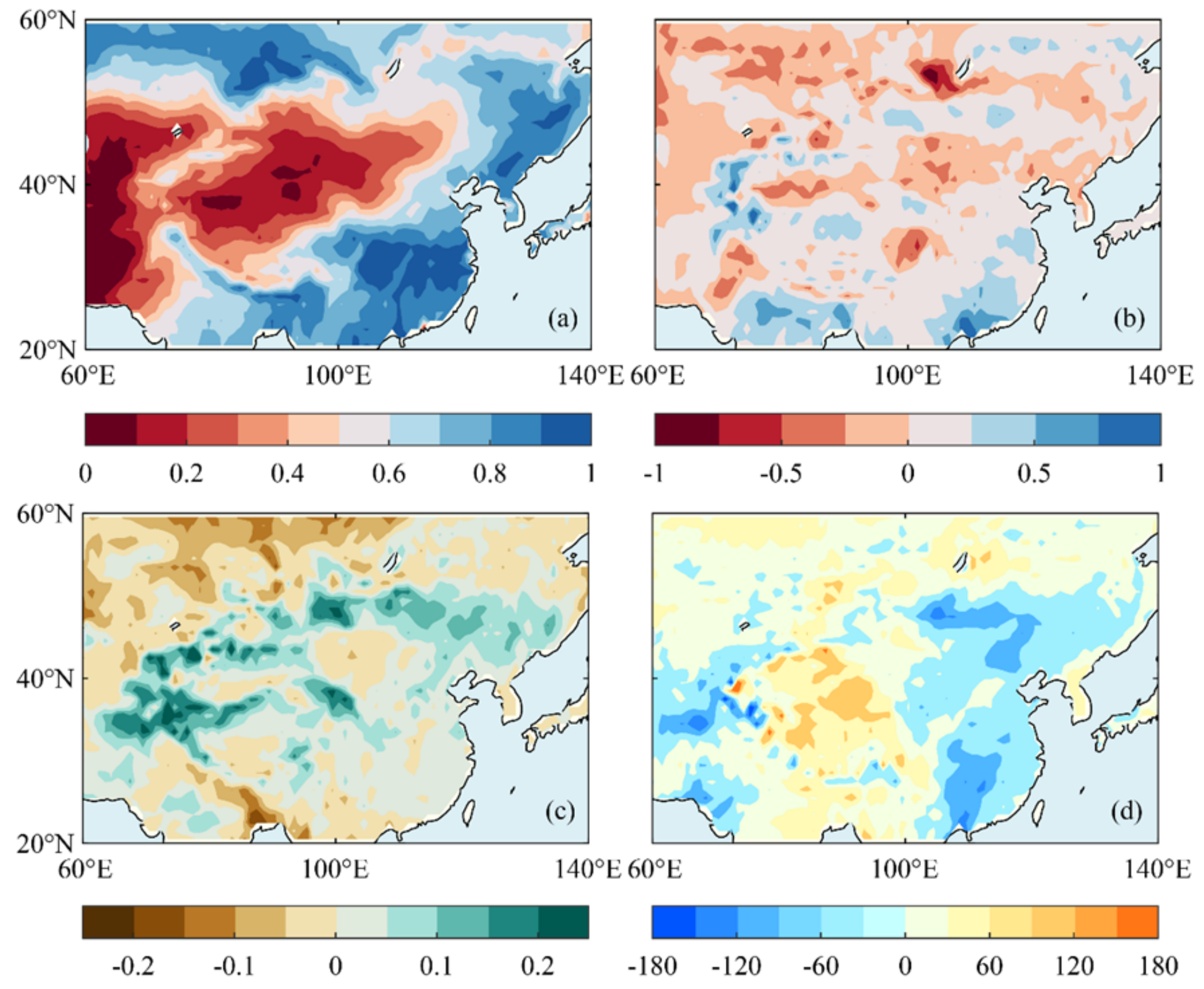

\section{Figure 9}

a Climate mean state and $b$ trend of the JJA evaporation fraction (EF, dimensionless) over Asian mid-low latitudes from 1980-2019. Trend of the c MJJ 0-40 cm SM (m3/m3/a) and d JJA land surface available energy (Rnet-GHF) from 1980-2019 